\title{
Green Synthesis and Charcterization of Silver Nanoparticles From Leafs Extracts of Rosa indica and its Antibacterial Activity Against Human Pathogen Bacteria
}

\author{
AMRITA RAJ ${ }^{1 *}$, REENA LAWRENCE ${ }^{2}$, KAPIL LAWRENCE $^{3}$, NEHA SILAS ${ }^{4}$, \\ MOHD. JALESS ${ }^{5}$ and RASHMI SRIVASTAVA ${ }^{6}$
1,2,4,5 Department of Chemistry, Sam Higginbottom, University of Agriculture Technology \& Science Allahabad, Uttar Pradesh 211003, India.
${ }^{3}$ Department of Molecular \& Cellular Engineering, Sam Higginbottom, University of Agriculture Technology \& Science, India.
${ }^{6}$ Department of Chemistry, Maharishi University, School of Science, lucknow, India.
${ }^{*}$ Corresponding author E-mail: amrita21101992@gmail.com

http://dx.doi.org/10.13005/ojc/340135

(Received: October 17, 2017; Accepted: November 01, 2017)

\begin{abstract}
S
This work was carried out for green synthesis of silver nanoparticles and investigation of its antibacterial activity. Rosa indica is of considerable interest and is well known compound because of its antioxidant, antidibetic, anti-inflammantry, antimicrobial activities. In the present study rapid and facile synthesis of silver nanoparticles at room temperature has been shown. On addition of plant extracts to Silver nitrate solution the change in color of the reaction mixture was obsereved which proved the formation of nanoparticles. Further, the green synthesised silver nanoparticles were characterized UV-Vis spectrophotometer, XRD analysis, FTIR, DLS, SEM with EDX. The average particles size of silver nanoparticles show between 1-100 nm through DLS anaylsis. Antibacterial activity of the Silver nanoparticles was evaluated by testing against Gram negative (Pseudomonas aeruginosa) and Gram positive( Bacillus subtilis) bacteria.
\end{abstract}

Keywords: Green synthesis, Rosa indica, Silver nanoparticles, Antibacterial activity.

\section{INTRODUCTION}

Nowdays, we are witnessing the development and advancement of a new interdisciplinary scientific field nanoscience. ${ }^{1}$ As was shown by numerous example in physics, chemistry and biology, a transition from macrosizes to those of 1-100 nm gives size to qualitative change

This is an $\mathbf{\sigma}$ Open Access article licensed under a Creative Commons Attribution-NonCommercial-ShareAlike 4.0 International License (https://creativecommons.org/licenses/by-nc-sa/4.0/ ), which permits unrestricted NonCommercial use, distribution and reproduction in any medium, provided the original work is properly cited. 
in physicochemical properties of individual compounds and system. The dependence of physicochemical properties on the partical size was magnetic properties, thermodynamics, electrochemistry, conductivity and electron transport. Nanochemistry is related with the production and reactions of nanoparticles and their compounds. ${ }^{2-4}$ It is concerned with the unique properties associated with assemblies of atom or molecules on a scale between that of the individual building blocks and the bulk material ( from 1 to 1000), ${ }^{5}$ At this level, quantum effect can be significant, and also new ways of carrying out chemical reation become possible. ${ }^{6}$ The science we methodologies from the synthetic chemistry and the material chemistry to obtain nanometerial with specific size, shapes, surface properties. Cross disciplinary nanoscience research involving physicts, chemists and engineers is concerned about the need of developing ecofriendly and sustainable methods for the synethesis of nanomaterials. ${ }^{7-9}$

There are many method for the synthesis of nanopartilces but one of the most conventional method is green synthesis because it is eco-frendily, non-toxic, very less expensive and very pure method. Nanoparticles having unique properties arising from their nanoscale dimensions. ${ }^{10-12}$ Nanoparticles has many important properties and various application in many areas such as drug, food, nutrition, electronics etc. ${ }^{13}$ The biological synthesis of nanoparticles which is very monodispersied particles with very specific sizes and shapes. The huge application in application in phamacutical company for successful remedical treatment as for disease. Green synthesis nanoparticles have great properties, which is synthesised by every part of plant such as, root, leaf, stem, flower, bark etc. ${ }^{14}$ In Synthesis of nanoparticles dried from are used. In Every plant have terpenoids ,alkanoids, Flavanoid, total phenolic content, which is help to synthesied the nanoparticles. ${ }^{15}$

The most researchers studied about nanoparticles. Today those nanoparticles are synthesised which are noble metals like silver ,zincoxide, gold, lead etc. But among the nanoparticles, silver and zincoxide nanopartilces play a excellence role in the field of biological and drug industry. There are two type of approach for the synthesis of nanparticles $-{ }^{16}$
- $\quad$ Top - down approaches
- $\quad$ Bottom - up approaches

The very good effect show bottom - up approach as compared to top - down approaches. The bottom - up approaches show best results to produced the nanoparticles without any defects. ${ }^{17}$

Their many potential for human health.Biosynthesis of silver and zincoxie nanoparticles by plant, bacteria, fungi, and yeast. There are many routes for the synthesis of nanoparicles such as biological, chemical, physical, hydrothermal, electrochemical, irradiative, photochemical method.but green synthesis method has one of the best method for the synthesis of nanoparticles. ${ }^{18-19}$

Rosa indica is a traditional medicinal plants and its belonging family Rosaceae. ${ }^{20}$ This plant have showing greatest advantages for stomach problem, and are being investigation for controlling cancer growth, constripation, inflammation, leucorrhea, heart and eye disease. Buds and Petal of Rosa indica used for removal of gal bladder and kidney and flower are used against asthma. It is commonly cultivated for fiber and most edible purposes and many used in medicinal purposes. The plant have more medicine value show like antioxidant, blood pressure, anti-dipression, anticancer, diuretic, antifungal, anti-immammatory anti-carcinogenic activity.

\section{MATERIALS}

\section{Plant collection}

The fresh leaves of Rosa indica were collected from Department of Horticulture, SHUATS Allahabad (State University), India.

\section{Chemicals}

Silver nitrate was analytical grade. Ultra-purified water used throughout the research work to prepare solution from a Merkmillipore-Milli$\mathrm{Q}$ water purification System. All glassware have been washed with sterile double distilled water and dried in an oven before use. 


\section{METHODS}

\section{Preparation of plant extract ${ }^{21}$}

Rosa indicaleaves were washed thoroughly under running deionised water and then rinsed thoroughly with ultra-purified water and dried at room temperature. The leaves are grinded to make a fine powder and used for experimental studies. The solution of leaf broth was prepared by taking $15 \mathrm{~g}$ leaves powder in a $150 \mathrm{ml}$ ulta-purified water (deionized water) and then boiled $30 \mathrm{~min}$. at the temperature $60{ }^{\circ} \mathrm{C}$. Then the leafs broth was cooled at room temperature then the leaf broth were filtrered using whatman filter paper before centrifuged at $3000 \mathrm{rpm}$ for $10 \mathrm{~min}$. for remove heavy metal and then leaf broth kept in refrigerators at $4{ }^{\circ} \mathrm{C}$ for further experimental use.

\section{Phytochemical analysis ${ }^{22-23}$}

Phytochemical analysis of leafs extracts of Rosa indicaananlysis by the spectra of UV-Vis spectrophotometer and FTIR .

\section{Green synthesis of silver nanoparticles ${ }^{21}$}

$5 \mathrm{ml}$ of leaf broth was added drop by drop to $45 \mathrm{ml}$ of $1 \mathrm{mM}$ aqueous silver nitrate solution using magnetic stirrer at room temperature, the solution become brown in color. Then the solution was centrifuged $5000 \mathrm{rpm}$ for $15 \mathrm{~min}$. Then it show formation of silver nanoparticles.

\section{Characterization of silver nanoparticles UV-Vis Spectrophtometer \\ UV-Vis spectroscopic studies were carried out on a Shimadzu UV-3600 Plus spectrophotometer at MNNIT Allahabad.}

\section{Dynamic light scatterring}

The average Particle size of the synthesized silver nanoparticles was evaluated with the help of a Nano Microtrac total solution in particles at MNNIT Allahabad.

\section{X-Ray Diffraction}

Silver nanoparticles was examined by X-Ray diffraction analysis using Rigaku Smart Lab. $\mathrm{X}$-ray diffractometer with $\mathrm{Cu} \mathrm{K} \alpha$ radiation monochromatic filter in the range of $10-90^{\circ}$ at MNNIT Allahabad Fourier transform- infra red FTIR spectra of silver nanoparticles was recorded by Perkin Elmer Spectrum Version 10.4.00.at MNIT Jaipur.

\section{Scanning electron microscopy with EDX}

SEM study was carried out to investigation the shape, size, and the surface area of the silver nanoparticles by ZEISS at IIT KANPUR.

\section{Anti-bacterial assay ${ }^{24}$}

Anti-bacterial activities were studied against Bacillus subtilis (MTCC 121) and Pseudomonas aeruginosa (MTCC 1688) strain. The antibacterial activity of Green synthesized of silver nanoparticles was testedagainst variou spositiove and negative bacteria by the agar well diffusion method. To examine the antibacterial activity of green synthesied AgNPs Muller- Hinton agar plates were sterilized and allowed to solidify. After solidification, $10 \mu$ of each bacterial suspension was inoculated on the petriplates by a sterile glass rod. Then, using sterile borer pounched four well into agar plates. Then we take three concentration, $25 \mu \mathrm{l}, 50 \mu \mathrm{l}, 75 \mu \mathrm{l}$ of silver nanoparticles was poured into well by the using of micropittete. Then we take a control (Amoxicillin) and the concentration of control is $25 \mu \mathrm{l}$, which is poured in one well of the agar plates. After that incubated for $24 \mathrm{~h}$ and at $37^{\circ} \mathrm{C}$, The were observed around the discs. Antibacterial activity was investigation by measuring the diameter of the zones of inhibition .

\section{Statistical analysis}

Two way of analysis variance (ANOVA) using in the result of antibacterial activity.

\section{RESULT AND DISCUSSION}

The first confirmation of green synthesis of silver nanoparticles by observation, During the visual observation, when addition of leaves extract of Rosa indica to $1 \mathrm{mM}$ solution of silver nitrate then the color of the solution changed from pale yellow to brown. This color change indicate the formation of silver nanoparticles. ${ }^{27}$ In this reation show the reduction of silver ions to silver nanoparticles. The solution of color arises due to the excitation of surface plasma vibration in silver nanoparticles (Figure.1).

\section{Phytochemical ananlysis of leafs extracts-}

The phytochemical ananlysis of leaves extract was examined spectroscopically. Phytochemical analysis of leafs broths was confirm by the instruments of UV-Vis Spectroscopy and 
FTIR. It is given confirmation that total phenolic group, antioxidant content, flavonoids, amines etc. formed in the plant extracts, these compounds confirm by IR band Which is used to as capping agent for the reduction of silver ion to silver nanoparticels.showen in Fig. 2 (A) and 3(B) .The UV-Vis spectroscopy confirm the presence of polyphenol in theleafs extracts. The absorbance of leafs extracts presented peak at $270 \mathrm{~nm}$ as characteristic of polyphenol molecules. This result also in according of the reported literature ${ }^{22}$ In FTIR Showing different functional groups in leaves extracts, that confirm the polyphenol groups present in plant extrats. Also this result are according of reported literatue. ${ }^{23}$
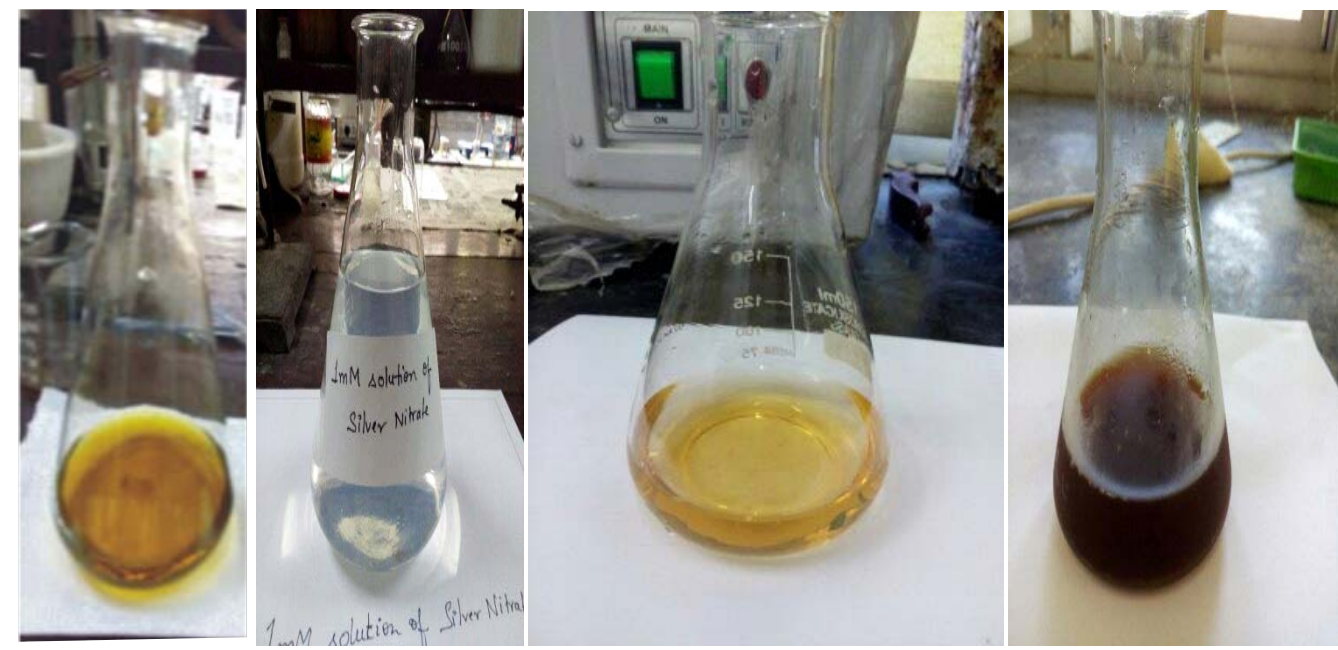

Fig. 1. Color Change indicating show formation of silver nanoparticles (A)Rosa indica leaves extracts (B) 1mMSolution of silver nitrate (C) and (D) show change the color from pale yellow to brown

\section{UV-Vis Spectrophotometer}

After observation, then the Green synthesisedof silver nanoparticles was first characterized from UV-Vis spectrophotometer. At the different time interval, the complete the reaction of green synthesied of silver nanoparticles the maximum absorbance peak are observe at $425 \mathrm{~nm}$. In the green synthesied silver nanoparticles showing
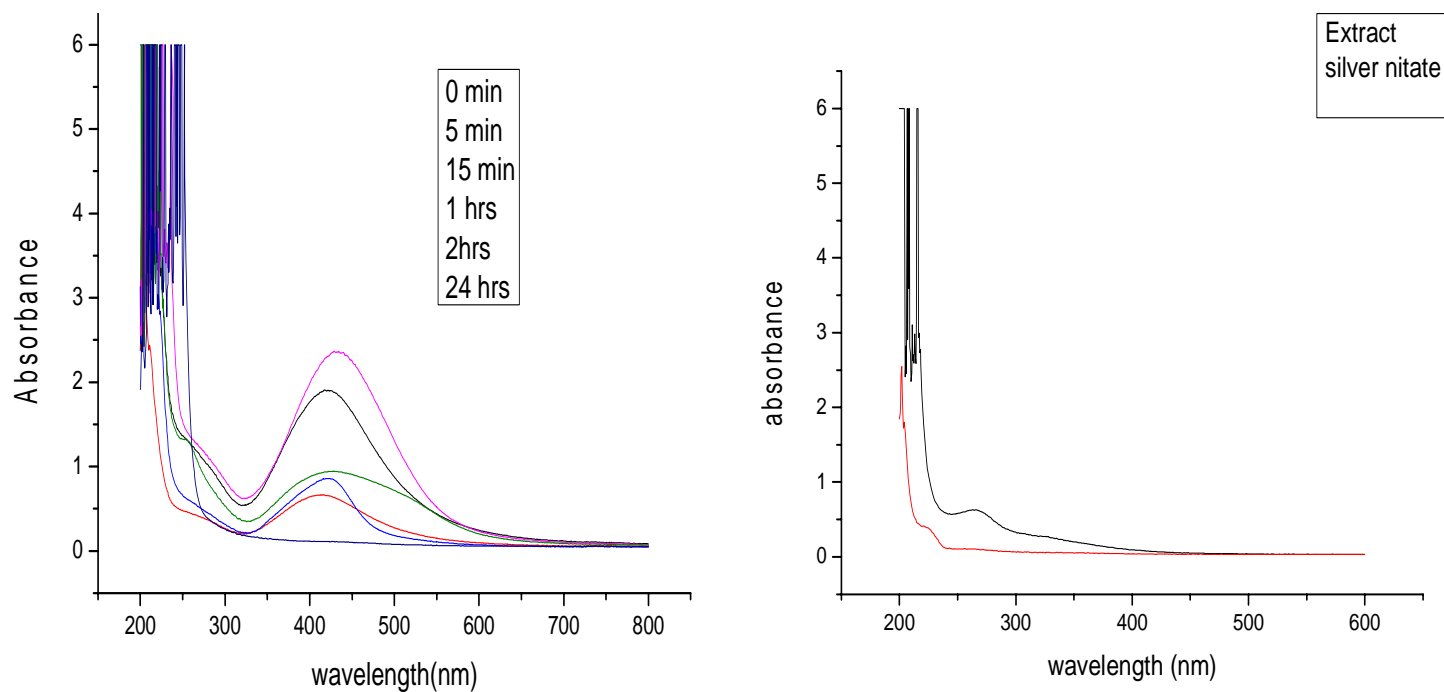

Fig. 2. A) UV-vis spectrophotometer showing peaks of leaves extracs and silver nitrate, B) Confirmation of silver nanoparticles at different time interval. 
strong surface plasma resonace band at $420 \mathrm{~nm}$ using Rosa indica leaves extrats. ${ }^{25}$ UV-Vis absorbance spectrophotometer is an most important chacterization for the showing the stability and formation of silver nanoparticles. In Fig B showing complete conversion of silver ion to silver nanoparticles.

\section{Fourier transform- infra red -}

FTIR is the one the most important characterization technique for the detecting the functional group in plant extract and silver nanoparticles, ${ }^{26-30}$ which is indicating to confirmation of silver nanoparticles. For, the reduction of silver

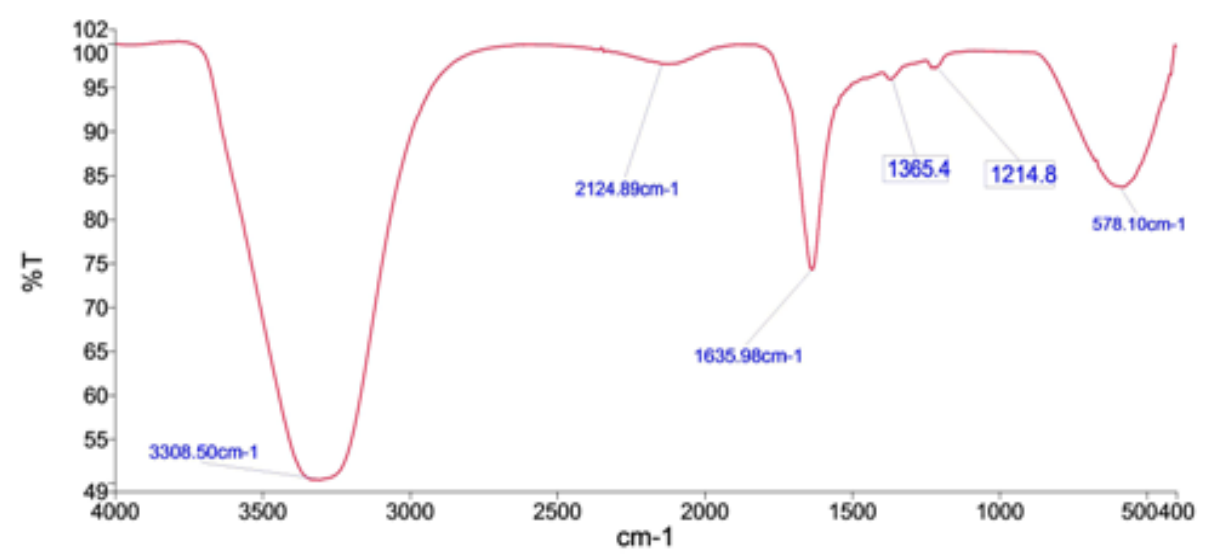

(a)

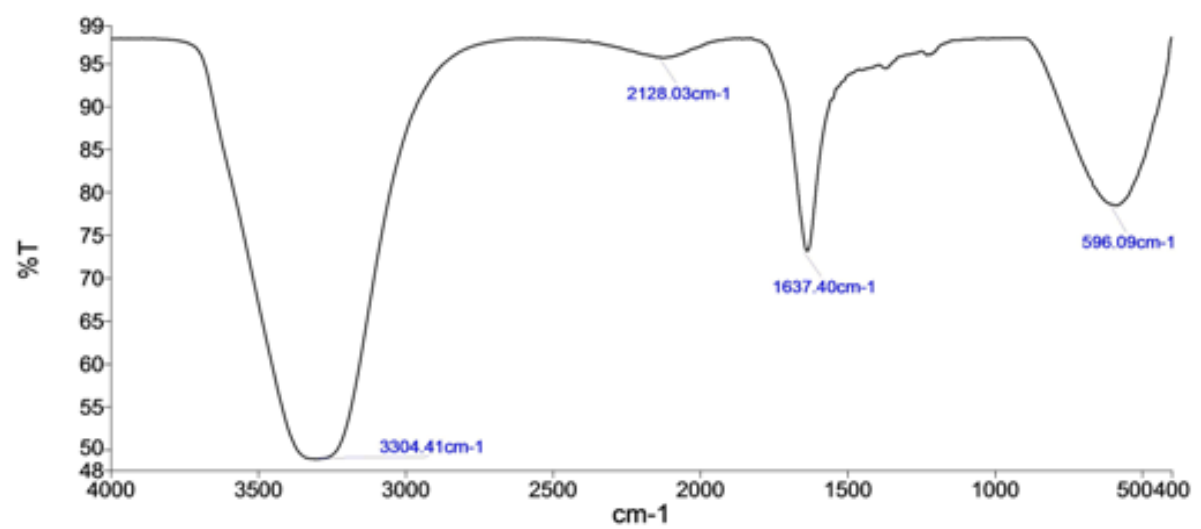

(b)

Fig. 3. FTIR Spectra A) Silver nanoparticles B) leaves extracts

nanoparticles the functional group of leaves extract is responsible for the reduction of silver ions.

The peak intensity of the spectrum showing different region of functional group in leaves extract and silver nanoparticles are analysed and showing in Figure. 3.

In FTIR spectra of silver nanoparticles and leaves extracts having more similarties with some difference between of position of peak. ${ }^{31-32}$ The most intense and broad peak was come in spectra at $3304 \mathrm{~cm}^{-1}$ corresponds to $\mathrm{OH}$ stretching vibrations of phenol and $-\mathrm{COOH}$ gorup present in leaves extracts. The peak located at $1635 \mathrm{~cm}^{-1}$ it was showing and indicating $\mathrm{C}=\mathrm{O}$ sterching and amide binding. At $2124 \mathrm{~cm}^{-1}$ peak obsevedby the alkanes present due to stretching. The nitro $\mathrm{N}-\mathrm{O}$ bending is assigned the peak at $1365 \mathrm{~cm}^{-1}$ and at $1214 \mathrm{~cm}^{-1}$ 
peak showing to $\mathrm{C}-\mathrm{O}-\mathrm{C}$ streching aromatic ring. At $578 \mathrm{~cm}^{-1}$ peak inicating to allkyl halides band for $\mathrm{C}-\mathrm{Cl}$. In FTIR spectra showing various gourp like carboxyl, carbonyl, amide, alkyl halide, phenol group of Rosa indica leaves extracts are used for the Green synthesis of silver nanoparticles. All goup are use as capping and stabilization agent in reduction of silver ion to silver nanoparticles .

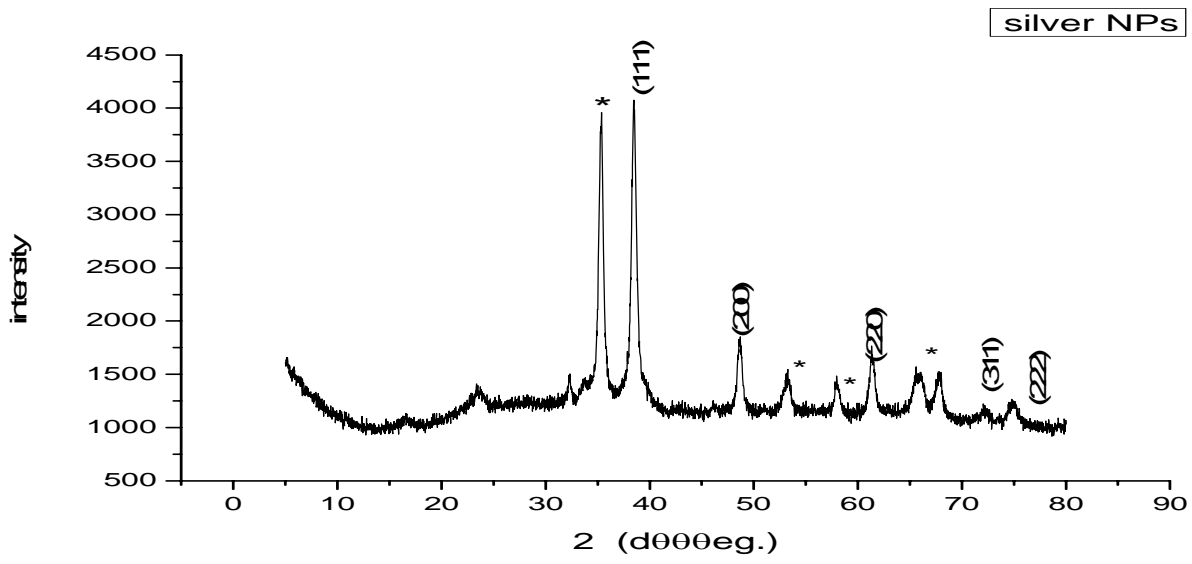

Fig. 4. X- Ray diffraction analysis of green synthesied nanoparticles

\section{X-Ray diffraction (XRD)}

The X-Ray diffraction characterization of sample was carried out to confirmation of green synthesied silver nanoparticles.

The five stong Bragg reflections formed at 2 theta value of $38.21^{\circ}, 44.11^{\circ}, 64.19^{\circ}, 77.56^{\circ}, 81.67^{\circ}$ corresponding to (111), (200), (220), (311), (222). Silver nanoparticles indicating strong, narrow and crystalline nature. ${ }^{33-34}$ The size of silver nanoparticles was formed by Debye - Scherrer formula given by the equation-

\section{$\mathrm{D}=\mathrm{K} \lambda /(\beta \cos \theta)$}

Where-

D- the crystal size

$\lambda$ - the wavelength of the $X$-ray radition $(\lambda=0.15406$ $\mathrm{nm}$ ) for CuKa,

K- usually taken as 0.89

$\mathrm{B}$ - the line width at half- maximum height

In XRD analyisis showing structural peaks and approximately size of crystalline of nanoparticles around $45-85 \mathrm{~nm}$. the green

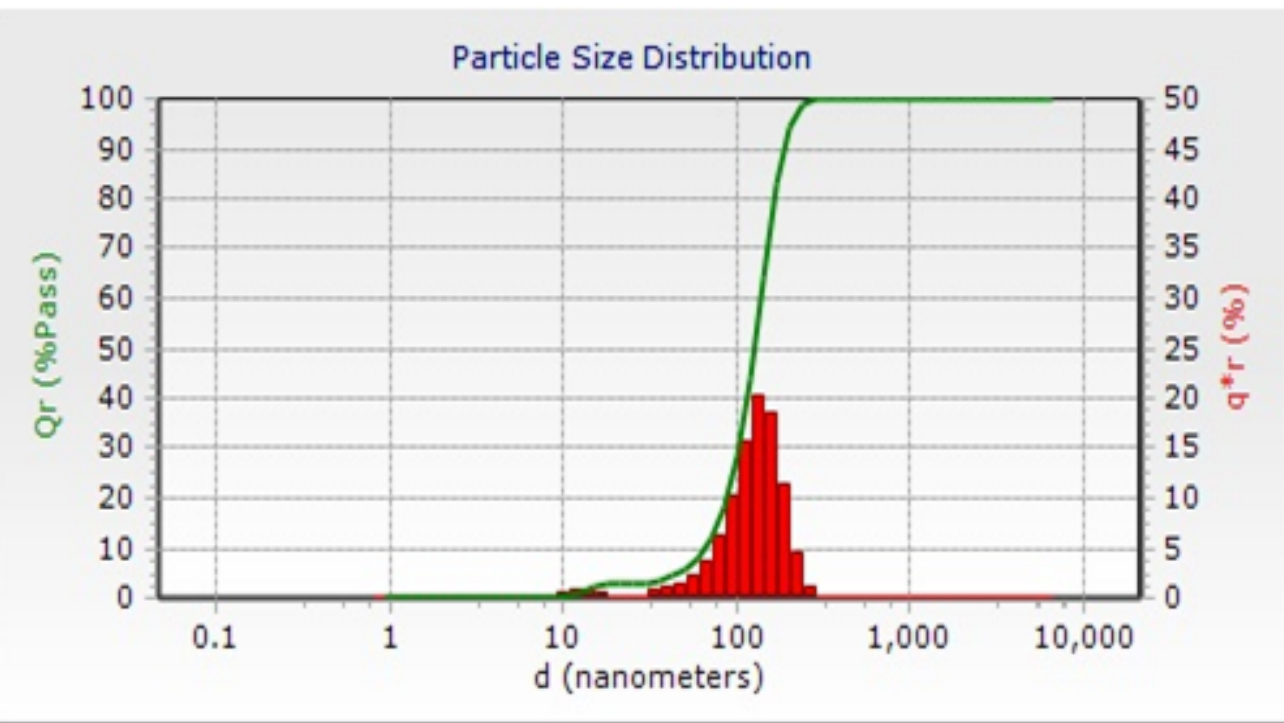

Fig. 5. Showing particles size distrubutionofgreensynthesied nanoparticles 
synthesied of silver nanoparticles show nano crystalline in nature. ${ }^{35}$ In XRD spectra show some extra peak, which is showed by stars, this peaks observed that the crystallization of bioorganic phase formed on the surface of Ag NPs. similar result was reported in silver nanoparticles using edible mushroom extract. ${ }^{38}$

\section{Dynamic Light Scattering (DLS)}

In dynamic light scattering used suspension of silver nanoparticles green synthesis from leaf exract from Rosa indica. The particle size distrubution though the DLS indicate the size of green synthesied nanoparticles between around 10 to $127 \mathrm{~nm}$. In this Fig V the very small amount of green syntheised silver nanoparticles are agglomerated showing in Figure.5.

\section{Scanning electron microsopy with EDX}

The solution of green synthesied of silver nanoparticles was formed by centrifuged at 15000 rpm at $20 \mathrm{~min}$. then the suspension and pellet are seperated the pellets again redispersed in ultrafine deionised water. The highly pure pellet was freeze then dried, then used for analysis. The surface morphology of silver nanoparticles was ananlysis using scanning electron microscopy with EDX. This figure show the confirmation of silver nanoparticles, which is synthesied by leafs extracts. The green synthesied silver nanoparticles were small amount
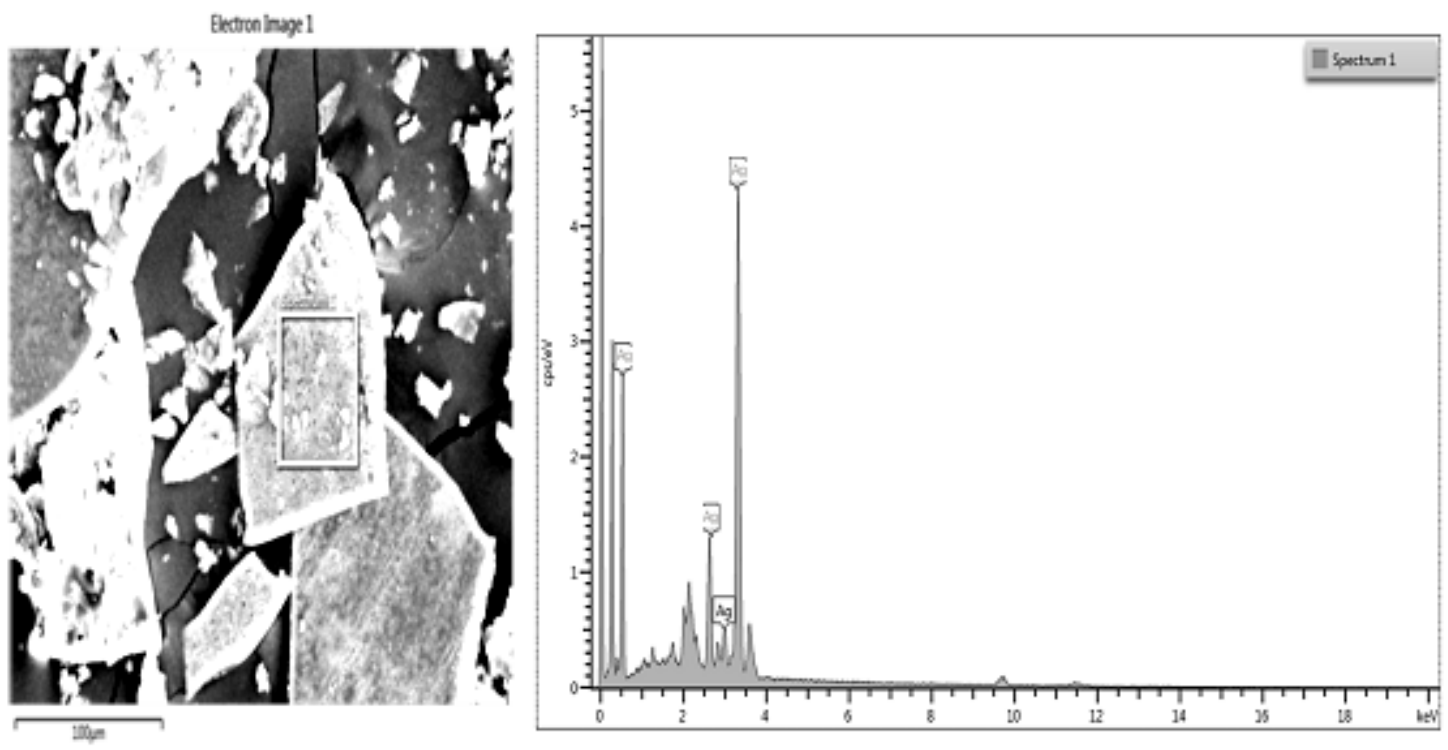

Fig. 6. Scanning electron microscopy with EDX

agglomerated. The green synthesied of silver nanoparticles are spherical in shape.$^{36}$ silver nanoparticles was futher confirmation by EDX. In EDX Fig showing strong peak which is indicating confirmation of AgNPs.

\section{Antimicrobial activity}

Antimicrobial acitivity was done by well diffusion method. The antimicrobial activity of green synthesied AgNPs was accomplished against Gram positive and Gram negaitive bacteria. The green synthesied Silver nanoparticles having excellent antimicrobial activity against Gram positive and Gram negaitive bacteria. In this paper, the Gram positive bacteria indicating the higestzone of inhibition and most effective as compared to Gram negaitive bacteria. The higest zone of inhibition was observed for $15 \mathrm{~mm}$ in B.subtilis and $14.5 \mathrm{in}$ $P$. aeruginosa at the higest concentration $7.5 \mu \mathrm{g} / \mu \mathrm{l}$. According to Fig $25 \mu \mathrm{l}$ concentration of amoxicillin showed mamxium radius of zone of inhibition of 21 against $B$.subtilis and 22.5 against P.aeruginosa. Silver nanoparticles have show most efficiency to inhibit the bacteria growth by the formation of 


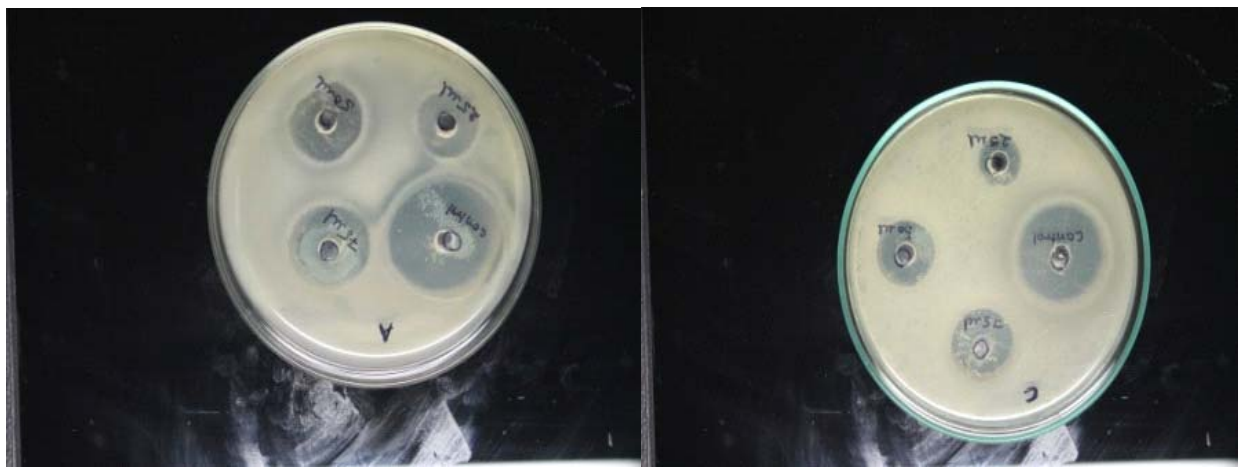

P.aeruginosa

B. subtilis

Fig. 7. Antibacterial activity of Silver nanoparticles synthesied against $P$. aeruginosa and $B$. subtilis

Table. 1: Zone of inhibition $(\mathrm{mm})$ obtained from well diffusion methods

\begin{tabular}{lcc}
\hline Concentrations $\mu \mathrm{g} / \mu \mathrm{l}$ & \multicolumn{2}{c}{ Zone of inhibition $(\mathrm{mm})$} \\
& P.aeruginosa & B.subtilis \\
\hline 25 & 7.9 & 8 \\
5 & 13.9 & 14.5 \\
75 & 14.9 & 15 \\
\hline
\end{tabular}

Disc's diameter- $5 \mathrm{~mm}$

ANOVA :

\begin{tabular}{lcccccccc}
\hline Source & d.f. & S.S. & M.S.S. & F. Cal. & F. Tab. 5\% & Result & S. Ed. ( \pm ) & C.D. at 5\% \\
\hline Due to zone inhibition & 1 & 0.107 & 0.107 & 2.56 & 18.51 & NS & 0.167 & 0.344 \\
Due to Concentration & 2 & 59.083 & 29.542 & 709 & 19.00 & S & 0.204 & 0.421 \\
Error & 2 & 0.083 & 0.042 & - & - & - & - & - \\
TOTAL & 5 & & - & - & - & - & - & - \\
\hline
\end{tabular}

reactive oxygen species and accumulation of nanoparticles. Silver nanoparticles act as bactericidal and bacteriostatic agents. ${ }^{37}$ In this result, using the statistical analysis by the annova software.

\section{CONCLUSION}

In this paper we study the green synthesied of silver nanoparticles from leaves of Rosa indica. In this rection leafs extracts used as capping agent for the stability of nanoparticles. Silver nanoparicles having sheperical shape and size of 1-100 nm. Its show excellent antibacterial activity against Gram positive and Gram neagaitive bacteria. We also agree to the methods of green synthesis of silver nanoparticles by UV-Vis, XRD, DLS, FTIR, SEM, EDX. This is eco-friendly, non-toxic, very conventional method.

\section{ACKNOWLEDGEMENT}

This authors wish to thanks MNNIT and SHUATS Allahabad for financial support and having given facilities 1 to carry out the research work. 


\section{REFERENCE}

1. Aragao, A.P.D.; Oliveira,T.M.D.; Quelemes, P.V.; Perfeito,M.L.G., Araujo.M.C.; Santiago, J.N.A.S.; Cardoso,V .S.; Quaresma, P.; Leite, J.R.D.S.D.A.; Silva, D.A.D.;Green synthesis of silver nanoparticles using the seaweed Gracilariabirdiae and their antibacterial activity., Arabian Journal of Chemistry, 2016, 1878-5352

2. Rajeshkumar,S.; Synthesis of silver nanoparticles using fresh bark of Pongamiapinnata and characterization of its antibacterial activity against gram positive and gram negative pathogens, Science Direct ResourceEfficient Technologies, 2016 , 2 , 30-35.

3. Nalwade. A.R., Sankala . K.D., Jagdale. K. B.;Poisonous weed leaf extract mediated biosynthesis of silver nanoparticles and evaluation of their antibacterial activity, Research in Pharmacy, 2013,3(4), 09-15.

4. M. Umadevi, M.R. Bindhu, V. SatheA Novel Synthesis of Malic Acid Capped Silver Nanoparticles using Solanumly copersicums Fruit Extract Sci Verse Science Direct J. Mater. Sci. Technol., 2013, 29(4), 317-322.

5. Kim,J.S.; Kuk, E.; Yu,K.N.; Kim, J.H.; Park,S.J.;Lee,H.J.; Kim, S.H.; Park,Y.K.; Park, Y.H.; Hwang,C.Y.;Kim,K.Y.;Yoon-SikLee, S.Y.; Jeong,D.H., Cho, H.M.; Antimicrobial effects of silver nanoparticles, Nanomedicine, Nanotechnology, Biology, and Medicine, 2007, 3 ,95- 101.

6. Abdel-Aziz.S.M.; Shaheen.M.S.;El-Nekeety. A.A.; Abdel-Wahhab.M.A.; Antioxidant and antibacterial activity of silver nanoparticles biosynthesized using Chenopodium murale leaf extract, Elsevier, King Saud University, 2013, 18, 1319-6103.

7. Vignesh. V., Anbarasi. K,F., Karthikeyenia.S., Sathiyanarayanan.G., Subramanian.P., Thirumurugana.R.; A superficial phytoassisted synthesis of silver nanoparticles and their assessment on hematological and biochemical parameters in Labeorohita (Hamilton, 1822) Colloids andSurfaces A:Physicochem. Eng. Aspects. 2013, 439,184- 192.

8. Kumar,C,G.; Poornachandra.Y.;Biodirected synthesis of Miconazole-conjugated bacterial silvernanoparticles and their application as antifungal agents and drugdelivery vehicles. Colloids and Surfaces B: Biointerfaces, 2015, 125,110-119.

9. Perni,S., Hakala.V., Prokopovich.P., Biogenic synthesis of antimicrobial silver nanoparticles capped withl-cysteine. Colloids and Surfaces A: Physicochem. Eng. Aspects, 2014, 460, 219-224 .

10. Gavade. N.L., Kadam.A.N.,Suwarnkar.M.B., Ghodake.V.P., Garadkar.K.M.;Biogenic synthesis of multi-applicative silver nanoparticles by using Ziziphus Jujuba leaf extract. Spectrochimica Acta Part A: Molecular and Biomolecular Spectroscopy, 2015, 136 , 953-960.

11. Dubey, S.P., Lahtinen. M., Särkka.H., Sillanpaa.M., Bioprospective of Sorbusaucuparia leaf extract in development of silver and gold nanocolloids Colloids and Surfaces $B$ : Biointerfaces, 2010, 80 , 26-33.

12. Singh.A.K., Talat.M., Singh.D.P., Srivastava.O.N.; Biosynthesis of gold and silver nanoparticles by natural precursor clove and their functionalization with amine group. J Nanopart Res, 2010, 12,1667-1675.

13. Vijayakumar.M., Priya.K., Nancy.F.T., Noorlidah.A.,, Ahmed.A.B.A.,Biosynthesis, characterisation and anti-bacterial effect of plant-mediated silver nanoparticles using Artemisia nilagirica. Industrial Crops and Products, 2013 , 41, 235- 240.

14. V.K. Vidhu, D. PhilipCatalytic degradation of organic dyes using biosynthesized silver nanoparticles Micron, 2014, 56, 54-62.

15. Barwal.I., Ranjan.P., Kateriya.S., Yadav.S.C.; Cellular oxido-reductive proteins of Chlamydomona sreinhardtii control the biosynthesis of silver nanoparticles Journal of Nanobiotechnology, 2011, 9, 56.

16. Boopathi.S.,Gopinath.S., Boopathi.T., Balamurugan.T., Rajeshkumar.R., Sundararaman.M., Characterization and Antimicrobial Properties of Silver and Silver Oxide Nanoparticles synthesized by CellFree Extract of a Mangrove- Associated Pseudomonas aeruginosa M6 Using Two Different Thermal Treatments Ind. Eng. Chem. Res. 2012, 51, 5976"5985.

17. Zhang.Y., Gao.G., Qian.Q., Cui.D.; Chloroplasts-mediated biosynthesis of nanoscale Au-Ag alloy for 2-butanone assay based on electrochemical sensor Nanoscale Research Letters, 2012, 7, 475.

18. Sathishkumar.M., Sneha.K., Won.S.W., , C.-W. Cho, S. Kim, Y.-S. Yun.; Cinnamon zeylanicumbark extract and powder mediated 
green synthesis of nano-crystalline silver particles and its bactericidal activity. Colloids and Surfaces B: Biointerfaces, 2009, 73, 332-338.

19. Vanaja.M., Annadurai.G.,Coleus aromaticus leaf extract mediated synthesis of silver nanoparticles and its bactericidal activity. Appl Nanosci., 2009, 3, 217-223.

20. Mishra R.P.; ArshadM.; and Sami, A.; Antibacterial Properties of Rosa indica(L.) Stem, Leaves and Flowers, JPBMS, 2011, 12(15).

21. Balen. K., Qing. W.,wang.Y., Liu.X., Palvannan.T., Wang.Y., Ma. F., and Zhang.Y., Antidiabetic activity of silver nanoparticles from green synthesis using Ionicera Japonica leaf extract. RSC Advance., 2016, 6, 40162-40168.

22. Leon,E.R.;Palomares, R,I.;Navarro,R.E.; Urbina,R.H.; Tonori, Judith.; Palomares,I.C.; Moldonado,A.;synthesis of silver nanoparticles using reducing agents obtained from natural sources Rumex hymensoplus extacts, Nanoscale Research letters, 2013, 8, 318.

23. Ahmed,S.; Ikram,S.; Silver nanoprticles : one pot green synthesis using Terminaliaarjuna Extact for Biological Application, J Nanomedicine Nanotechnology., 2015 , 6, 4.

24. A, R. Allafchian, S.Z. Mirahmadi, S.A.H. jalali, S.S hashemi, M.R.Vahabi (2016).Green synthesis of silver nanoparticles using phlomis leaf extract and investigation of their antibacterial activity. Journal of Nanostructure in Chemistry, 2016, 6, 129-135 .

25. Song.J.,Wu.F., Wan.Y., Ma.y.;Colorimetric detection of melamine in pretreated milk using silver nanoparticles functionalized with sulfanilic acid. Food Control., 2015, 50, 356-361.

26. Hei.H., Hong H., Wang.R., Liu.L., Zhang.G., Controlled Synthesis and Characterization of Noble Metal Nanoparticles. Soft Nanoscience Letters., 2012 , 2, 34-40.

27. S. Lokina., A. Stephen ., V. Kaviyarasan., C. Arulvasu ., V. Narayanan.; Cytotoxicity and antimicrobial activities of green synthesized silver Nanoparticles European Journal of Medicinal Chemistry, 2014, 76 , 256-263.

28. Shankar.S.,Chorachoo.J., Jaiswal.L., Voravuthikunchai. S.P., Effect of reducing agent concentrations and temperature on characteristics and antimicrobial activity of silver nanoparticles. Materials Letters. 2014, 137, 160-163.

29. Edison.T.N.J.I., Sethuraman. M.G., Electrocatalytic Reduction of Benzyl Chloride by Green Synthesized Silver
Nanoparticles Using Pod Extract of Acacia niloticaACS Sustainable Chem. Eng., (2013), 1, 1326-1332.

30. Singh.A.K., Tripathi.Y.B., Pandey.N., Singh.D.P., Tripathi.D., Srivastava.O.N., Enhanced antilipopoly saccharide (LPS) induced changes in macrophage functions by Rubiacordifolia (RC) embedded with $\mathrm{Au}$ nanoparticles. Free Radical Biology and Medicine, 2013, 65, 217-223.

31. Mudasir A. D., Ingle.A.,Rai.M., Enhanced antimicrobial activity of silver nanoparticles synthesized by Cryphonectria sp. evaluated singly and in combination with antibiotics. Nanomedicine: Nanotechnology, Biology, and Medicine, 2013, 9, 105-110.

32. Pant.G., Nayak.G., Prasuna.R.G., Enhancement of antidandruff activity of shampooby biosynthesized silver nanoparticles from Solanumtrilo batum plantle af Appl Nanosc.i, 2013, 3, 431-439.

33. Gunasekar.V.,Divya.B. Brinda.K., Vijay krishnan. J.,Ponnusami.V., Rajan. K.S. Enzyme mediated synthesis of $\mathrm{Ag}-\mathrm{TiO}_{2}$ photocatalyst for visible light degradation of reactive dye from aqueous solution. J Sol-Gel Sci Technol, 2013, 68, 60-66.

34. Mishra.A., Kaushik.N.K., Sardar.M., Sahal.D., Evaluation of antiplasmodial activity of green synthesized silver nanoparticles Colloids and Surfaces B: Biointerfaces, 2013, 111, 713- 718.

35. Zahir.A.A.,Rahuman.A..A.; Evaluation of different extracts and synthesised silver nanoparticles from leaves of Euphorbia prostrata against Haemaphy salisbispinosa and Hippobosca maculate Veterinary Parasitology, 2012, 187, 511- 520.

36. Dhanasekaran.D.,Thangaraj.R.; Evaluation of larvicidal activity of biogenic nanoparticles against filariasis causing Culex mosquito vector Asian Pac J Trop Dis., 2013, 3(3), 174-179.

37. Santhoshkumar.T.,Rahuman.A.A., Bagavan.A., Marimuthu.S.,Evaluation of stem aqueous extract and synthesized silver nanoparticles using Cissusquadrangularis against Hippoboscamaculata and Rhipicephalus (Boophilus) microplus. Experimental Parasitology., 2012, 132, 156-165.

38. Philip. D.; Biosynthesis of Au, ag and Au-Ag nanoparticles using edible mushroom extract. Spectrochimica Acts Part A : Molecular and Biomolecular spectroscopy., 2009, 73, 374-381. 